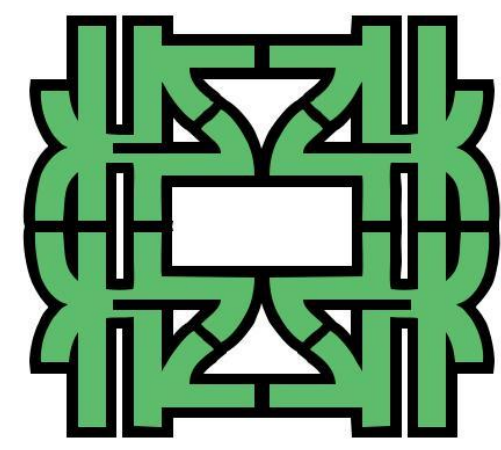

Aslan

KURIKULUM PENDIDIKAN VS KURIKULUM SINETRON

Wahyudin

KEPEMIMPINAN PERGURUAN

DALAM PERSPEKTIF TEORI INTERAKSIONISME SIMBOLIK

DAN DRAMATURGI 

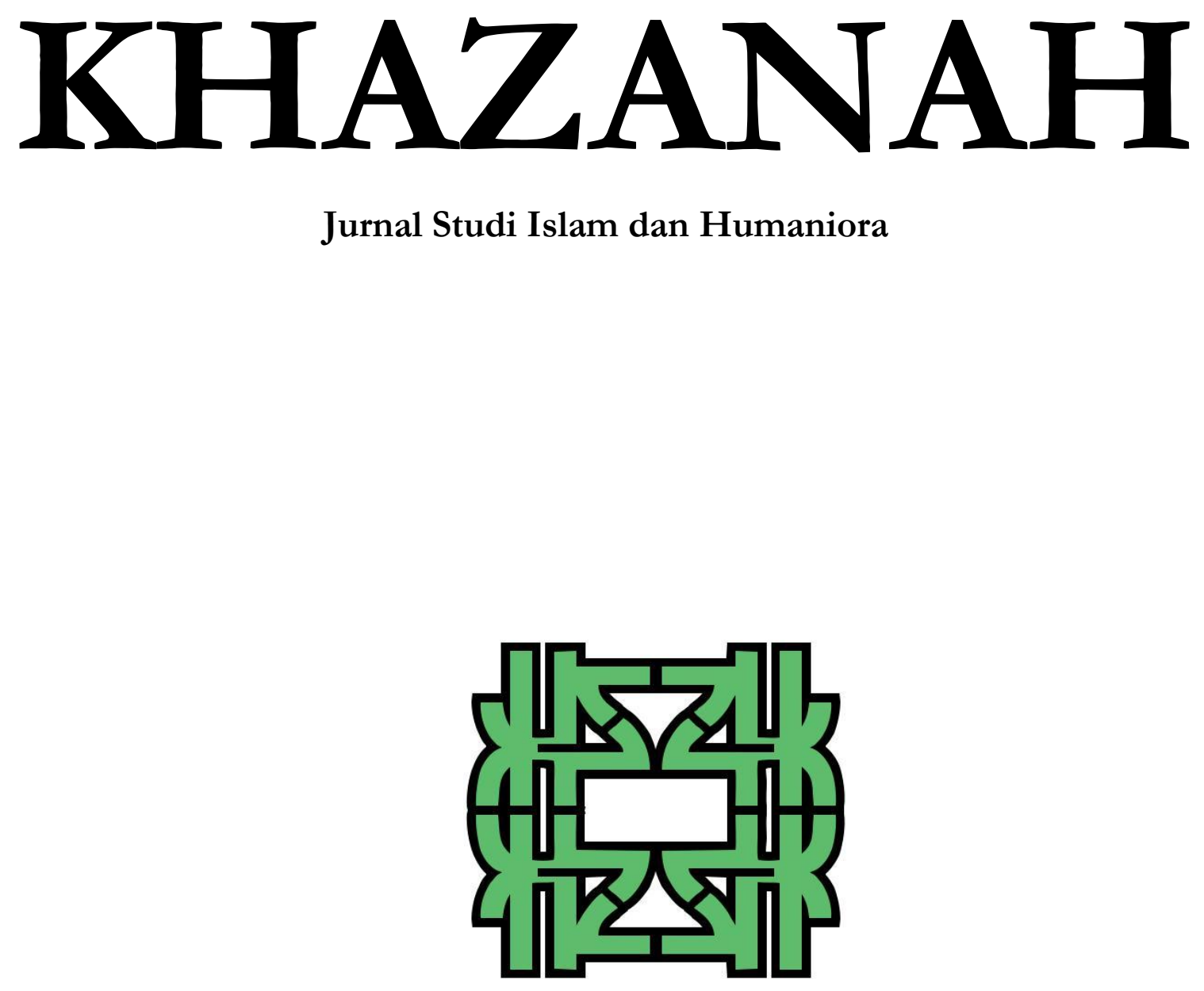
Volume XIV, Nomor 02, 2016

ISSN: 0215-837X E-ISSN ONLINE: 2460-7606

\section{EDITOR-IN-CHIEF}

Muhammad Zainal Abidin

\section{MANAGING EDITOR}

Anwar Hafidzi

\section{EDITORIAL BOARDS}

Mujiburrahman, (Antasari State Islamic University of Banjarmasin, Indonesia)

Syaifuddin Sabda, (Antasari State Islamic University of Banjarmasin, Indonesia)

Fathi Hasan Malkawi, (International Institute of Islamic Thought (IIIT), Amman, Jordan)

Masdar Hilmy, (Sunan Ampel State Islamic University of Surabaya, Indonesia)

Kautsar Azhari Noer, (Syarif Hidayatullah State Islamic University of Jakarta, Indonesia)

Zakiyuddin Baidhawy, (Salatiga State Islamic Institute, Indonesia)

Ahmad Rafiq, (Sunan Kalijaga State Islamic University of Yogyakarta, Indonesia)

\section{EDITORS}

Ammar Fauzi, (Sadra International Institute Jakarta)

Mujiburohman (Michigan State University, USA)

Najib Kailani (Sunan Kalijaga State Islamic University of Yogyakarta, Indonesia)

Wardani, (Antasari State Islamic University of Banjarmasin, Indonesia)

Muhammad Rusydi, (Antasari State Islamic University of Banjarmasin, Indonesia)

\section{EXECUTIVE EDITOR}

\section{Yokke Andini}

Wardatun Nadhiroh

Mohammad Iqbal Assyauqi

Mariatul Asiah 


\title{
KURIKULUM PENDIDIKAN VS KURIKULUM SINETRON
}

\author{
Aslan \\ Dosen Tetap Institut Agama Islam Sultan Muhammad Syafiuddin Sambas \\ Jl. Raya Sejangkung, Kawasan Desa Sebayan, Tumuk Manggis, Kecamtan Sambas, \\ Kabupaten Sambas, Kalimantan Barat 79463 \\ e-mail: aslanmarani@yahoo.com
}

\begin{abstract}
In line with the times, todays' curriculum in Indonesia is always changing. The curriculum is vulnerable to social change. This is due to the existence of behavior differences in learners that tend to be negative from year to year, so that the government has to replace the curriculum with various names, objectives and outputs generated. Yet, current technological developments have affected the output of current education, so that the sinetron curriculum is more successful than the education curriculum.
\end{abstract}

Keywords: curriculum, change, system, principle, education

\begin{abstract}
Abstrak
Kurikulum yang ada di Indonesia saat ini selalu berubah-ubah sesuai dengan perkembangan zaman. Kurikulum rentan terhadap perubahan sosial. Hal ini disebabkan, adanya tingkah laku perbedaan peserta didik dari tahun ke tahun yang mengalami penurunan bukan kenaikan, sehingga mau tidak mau Pemerintah harus mengganti kurikulum dengan berbagai macam namanya, tujuannya dan output yang dihasilkan. Akan tetapi, adanya perkembangan teknologi saat ini, telah mempengaruhi hasil output pendidikan saat ini, sehingga kurikulum sinetron lebih berhasil ketimbang kurikulum pendidikan.
\end{abstract}

Kata kunci: kurikulum, perubahan, system, prinsip, pendidikan

\section{Pendahuluan}

Kurikulum pendidikan yang ada di Indonesia ini, terus berganti seiring dengan perjalanan waktu. Tujuan pergantian tersebut adalah sebagai pembaharuan terhadap kurikulum lama yang dianggap sudah usang atau sudah ketertinggalan zaman. Dalam hal 
ini, saya menganggap bahwa kurikulum adalah ibarat seorang pacar., karena jika tidak cocok maka akan diputuskan dan dicari pacar yang baru sebagai pengganti pacar yang lama walaupun sudah menjalin hubungan dengan waktu yang cukup lama dengan janjijanji manis yang telah diucapkan dan tujuannya hanya untuk mengantarkan dalam ikatan yang sah, yakni perkahwinan. Tetapi, apakah daya jika tidak berjodoh, walaupun janji manis masih selalu terngiang ditelinga tidak akan dapat menjadi suami istri, sebagai tujuan dari berpacaran tersebut. Begitu juga halnya, jika terjadi sebaliknya, maka tujuan jalinan itu tercapat tetapi belum tentu menjadi keluarga sakinah, mawaddah dan warahmah.

Keterkaitan kurikulum dengan ibarat sebuah pacar adalah tidak bisa bertahan lama. Kurikulum rentan terhadap perubahan sosial. Oleh karena itu, kurikulum selalu mengalami perubahan seiring dengan zaman perubahan tersebut. Saat ini, kurikulum sinetron dapat membuat penonton terkesema dengan adegan yang telah dibuat sesuai dengan prosedurnya. Jika ditelusuri, kurikulum sinetron tidak mengajarkan nilai-nilai positif, tetapi hanya banyak mengajarkan nilai-nilai negatif seperti sinetron "Roman Picisan”. Sinetron ini, hanya memperebutkan seorang cowok sehingga rela bertengkar dan berbuat amoral. Akan tetapi, model kurikulum seperti ini, mudah diserap oleh anak di zaman era modernisasi saat ini. Padahal, pada kenyataannya dari sinetron tersebut, tidak sesuai dengan fakta yang sebenarnya.

Bahkan, hal yang paling menarik lagi adalah program permasalahan cinta, dengan menyoroti berbagai macam tingkah-laku yang dilakukan pasangan yang dicurigai ada hubungan dengan wanita lain atau pria lain sudah hadir dilayar televisi saat ini. Program tersebut dikenal sebagai "Katakan Putus". Program ini, hanya membantu permasalahan cinta bukan membantu tujuan akhir cinta tersebut, yakni sampai jenjang pernikahan.

Berdasarkan paparan diatas, memberi gambaran kepada kita semua, bahwa kurikulum sinetron lebih berhasil ketimbang kurikulum pendidikan. Mengapa, kurikulum saya kaitkan dengan sinetron., karena kurikulum adalah sebuah program yang dibuat sedemikian rupa untuk diimplementasikan ke sekolah-sekolah yang hasilnya dapat terlihat dari perubahan tingkah laku anak didik. Begitu juga halnya dengan sinetron. Sinetron adalah sebuah program yang dibuat oleh sutradara dengan diperankan oleh 
artis-artis yang sudah ahli dalam bidangnya untuk membuat sebuah adegan yang benarbenar terjadi sehingga mempengaruhi para penontonya. Adegan yang diperankan oleh artis tersebut, adalah sama seperti implementasi kurikulum., tetapi implementasi kurikulum sinetron lebih banyak kelihatan hasilnya daripada kurikulum pendidikan. Hal ini sangat terlihat dengan jelas, bahwa hasil kurikulum sinetron telah menyeret waktu anak, sehingga banyak penonton yang lupa waktu bekerja, shalat, bersilaturahmi karena gara-gara menunggu sinetron yang digemarinya.

Berdasarkan survey yang telah dilakukan di "Jakarta, Bandung, Semarang, Surabaya, Medan dan Makasar" tentang kegiatan sehari-hari yang dilakukan oleh anakanak. Dalam survey tersebut, dilaksanakan pada anak berumur 7-14 tahun dan ibu dari anak berusia 0-14 tahun dengan strata sosial yang berbeda-beda. Hasil dari survey tersebut, menunjukkan bahwa anak sudah terbiasa dengan televisi sejak bayi sebanyak 25\%. Setelah menginjak lebih dari satu tahun, anak-anak dalam melakukan kegiatannya tidak terlepas dari televisi sebanyak 92\%. Dan setelah menginjak pada usia masuk TK sampai ke SMP, anak-anak sudah menjadi penggemar televisi. Kehadiran televisi dalam hidup anak-anak dengan adegan iklan yang menarik dan pembunuhan telah membawa pesona anak dalam dunia khayal. ${ }^{1}$

Dinamika-dinamika kehidupan dunia maya tersebut, tidak kalah pentingnya dengan dinamika kurikulum pendidikan saat ini. Bahkan kurikulum sinetron lebih berhasil ketimbang kurikulum pendidikan. Hal ini terbutki pada kurikulum sinetron yang diikuti oleh flowers, hampir ribuan orang atau bahkan jutaan orang ingin bertemu dengan tokoh artis tersebut. Berbeda halnya dengan kurikulum pendidikan yang hanya sedikit terlihat dari hasil output anak didik, jika dikaitkan dengan memperoleh pekerjaan sesuai dengan profesinya.

Berdasarkan dinamika-dinamika tersebut, artikel ini menyoroti keberhasilan kurikulum dari anak didik yang memperoleh pendidikan di zaman era globalisasi saat ini dan kesempatan peluang dalam mencari pekerjaan sesuai dengan profesi Jurusan/Prodi yang diambilnya.

1 Sigit Muryono, Empati: Penalaran Moral Dan Pola Asuh: Telaah Bimbingan Konseling (Yogyakarta: Cawan Mas, 2009), h. 6-7. 


\section{Kurikulum}

Kurikulum berasal dari bahasa latin yakni "curro atau currere dan ula atau ulums, berupa kata kerja to run yang berarti lari cepat atau menjalani, kemudian menjadi kata benda curricula atau curriculum". Sementara, jika dikaitkan dengan pendidikan kurikulum adalah sejumlah mata pelajaran yang harus dikuasai oleh peserta didik. ${ }^{2}$

Dari penjelasan tersebut, hal yang menarik tentang kurikulum adalah "berlari atau menjalani”. Manusia setiap berolah raga dengan berlari pasti dimulai dari start sampai finish. Setiap yang start pasti bisa dilalui tanpa ada beban maupun halangan, tetapi setiap finish pasti ada saja halangan ataupun hambatan bahkan tidak sampai finish yang disebabkan oleh beberapa faktor tertentu yang tidak bisa untuk menyelesaikannya sampai finish. Sedangkan kurikulum dalam arti "menjalani" tergantung manusianya dalam menjalaninya, karena ia yang menentukan hidupnya, mau berhasil atau tidak. Kurikulum adalah kompas, yang hanya membantu peserta didik untuk menunjukkan arah agar tidak tersesat di jalan. Kurikulum hanyalah sebuah program yang dibuat oleh pemerintah dan hasilnya tergantung guru yang mengajarkan kepada anak, seperti halnya dengan program "Katakan Putus" yang penulis maksud. Oleh karena itu, output kurikulum tergantung Sumber Daya Manusianya dalam menentukan hidupnya.

Untuk lebih jelasnya, coba kita lihat definisi kurikulum menurut pakarnya, diantaranya: ${ }^{3}$

1. Hilda Taba, mengartikan "kurikulum sebagai "a plan for learning";

2. J. Galen Saylor dan William M. Alexander, menjelaskan "The curriculum is the sum total of schools effort to influence learning, whether in the classroom, on the playground, or out of school";

3. Harold B. Alberty cs., kurikulum sebagai "all of the activities that the provided for the students by the school".,d) B. Othanel Smith cs., "kurikulum sebagai sejumlah pengalaman yang secara potensial dapat diberikan kepada anak, yang diperlukan agar mereka dapat berpikir dan berkelakuan sesuai dengan masyarakatnya";

4. J. Lloyd Trump dan Delmas F. Miller, "kurikulum lebih luas dari pada hanya bahan pelajaran, dalam kurikulum termasuk metode belajar dan mengajar, cara mengevaluasi kemajuan murid dan seluruh program, perubahan dalam tenaga pengajar, bimbingan dan penyuluhan, supervisi dan administrasi dan hal-hal

2 Salamah, Pengembangan Model Kurikulum Holistik: Pendidikan Agama Islam Pada Madrasah Tsanawiyah (Yogyakarta: Aswaja Pressindo, 2011), h. 13.

3 I Made Kartika, Pengertian Peranan dan Fungsi Kurikulum (FKIP: Universitas Dwijendra Denpasar, tth), h. 1-2. 
struktural mengenai waktu, jumlah, ruangan serta kemungkinan adanya pilihan mata pelajaran";

5. Alice Miel, "kurikulum meliputi segala pengalaman dan pengaruh yang bercorak pendidikan yang diperoleh anak di sekolah";

6. Depdikbud, "kurikulum dipandang sebagai suatu program pendidikan yang direncanakan dan dilaksanakan untuk mencapai sejumlah tujuan-tujuan pendidikan tertentu. Dari definisi ini mencerminkan adanya: a). Pendidikan itu adalah suatu usaha atau kegiatan yang bertujuan; b). Di dalam kegiatan pendidikan itu terdapat suatu rencana yang disusun/diatur; c). Rencana tersebut dilaksanakan di sekolah melalui cara yang telah ditetapkan";

7. Kurikulum adalah "seperangkat rencana dan pengaturan mengenai tujuan, isi dan bahan pelajaran serta cara yang digunakan sebagai pedoman penyelenggaraan kegiatan pembelajaran untuk mencapai tujuan pendidikan tertentu. (UU. No. 20 tahun 2003 tentang Sistem Pendidikan Nasional)".

Kurikulum yang telah dipaparkan oleh pakar-pakar barat tersebut, hampir sama dengan pengertian kurikulum pendidikan Islam, cuma beda katanya tanpa merubah maknanya. Dalam Islam, kurikulum disebut "manhaj” atau jalan yang ditempuh oleh anak didik. Tujuannya untuk membentuk perilaku anak agar mengarah kepada hal yang positif. $^{4}$

Oleh karena itu, tujuan kurikulum pada dasarnya adalah sama yakni mencerdaskan bangsa. Akan tetapi, pakar kurikulum tersebut, dalam membuat definisi kurikulum tersebut, tidak terlepas dari sejarah yang dilaluinya, sehingga membuat definisi pun berbeda-beda. Seingat pengetahuan saya, pada zaman dahulu orang berdebat dan ingin menjadi terkenal dan dikenali melalui tulisannya yang telah menjadi buku. Pada saat era modernisasi sekarang ini, orang berdebat sudah melalui media sosial, misalnya "facebook". Jika yang banyak "like" dan komentar, sudah dianggap terkenal dan dikenali.

Paparan diatas, hanya untuk memperjelas ruh kurikulum yang sebenarnya. Secara fitrahnya, ruh kurikulum, bukan saja mampu untuk mencerdaskan bangsa tetapi mampu menghantarkan anak didik dalam dunia kerja. Saat ini, kurikulum dianggap belum mampu untuk menghantarkan anak pada bidang kerja sesuai dengan profesinya, tetapi kurikulum hanya mampu mengantarkan anak pada jenjang perkahwinan. Hal ini terbukti

4 Sariono," Kurikulum 2013: Kurikulum Generasi Emas," E-Jurnal Dinas Pendidikan Kota Surabaya, Vol. 3, (tth): h. 1. 
dengan kejadian saat ini, banyak anak yang menikah dibawah umur bahkan masih sekolah ataupun kuliah.

Kurikulum sinetron lebih berhasil ketimbang daripada kurikulum pendidikan. Kurikulum sinetron mencetak anak didiknya untuk pandai berakting dengan menghasilkan uang yang melimpah ruah. Kurikulum pendidikan mencetak manusia sesuai dengan Jurusan/prodi yang diambilnya, tetapi hanya menghasilkan uang yang tidak sebanding dengan biaya yang dikeluarkannya. Maka, selayaknya bagi pengamat kurikulum, seharusnya kita mencontoh dari Negara yang sudah berhasil dalam implementasi kurikulum dan output yang dihasilkannya, misalnya Negara Finlandia.

\section{Prinsip kurikulum}

Pendidikan yang ditempuh oleh anak didik, tidak terlepas untuk menjadi orang yang sukses dalam dunia kerja. Oleh karena itu, anak dalam memilih tempat kuliah dicarikan oleh orangtuanya yang paling berkelas, agar nantinya anak mendapat pekerjaan yang berkelas juga. Pada saat saya selesai melaksanakan pendidikan di Tingkat Atas, pekerjaan yang paling dianggap bermutu adalah menjadi Polisi, Bidan dan Perawat. Pada saat itu, banyak anak-anak yang ingin menjadi polisi, bahkan mengeluarkan biaya ratusan juta pun untuk menjadi polisi dianggap biasa saja. Begitu juga halnya, ingin menjadi Bidan dan Perawat. Jika tidak diterima di Universitas Provinsi, maka mencari Universitas di luar daerah, yang penting, bisa menjadi Bidan atau Perawat, walaupun jauh yang penting selesainya nanti lansung bisa kerja.

Dari paparan tersebut, sama juga halnya dengan prinsip kurikulum, tetapi prinsip ruh kurikulumnya sudah tidak ada, karena mencari pekerjaan bukan didasari ijazahnya tetapi didasari dengan uang. Karena setiap melamar pekerjaan, harus didasari dengan pelumasnya agar mudah diterima, yakni uang.

Prinsip ruh kurikulum yang secara fitrahnya adalah "relevansi, efektivitas, efisiensi dan fleksibelitas". ${ }^{5}$ Kurikulum selalu mengalami perubahan yang tujuannya mampu untuk menghadapi tantangan zaman, yang dinamakan relevansi. Kurikulum mampu mengantarkan anak ke dunia kerja yang berarti efektivitas. Kurikulum sesuai dengan tingkat anak-anak yang dinamakan efisiensi. Kurikulum sesuai dengan program

5 I Made Kartika, Pengertian Peranan dan Fungsi Kurikulum,..., h. 7. 
yang telah dibuat untuk di implementasikan ke sekolah-sekolah yang dinamakan fleksibelitas.

Akan tetapi, prinsip kurikulum tersebut, menurut saya, hanya sebagian yang mampu dan sebagian belum mampu, ibaratnya sama-sama menghasilkan 50\%. Namun, hal yang menarik untuk disoroti saat ini adalah kurikulum masih belum mampu untuk menghasilkan output sesuai dengan Jurusan/Prodi yang diambil oleh anak dalam melanjutkan kuliahnya.

Menurut Bambang Sugiharto, saat ini pendidikan telah menjadi lembaga ekonomi yang telah menjual ilmu pengetahuan, sehingga output dari kurikulum telah menghasilkan anak yang ahli dalam profesinya tetapi tidak ahli dalam bidang kerjanya. ${ }^{6}$ Selain itu, secara fitrahnya, ruh-ruh seorang pendidik, ikut juga hilang., karena pada dasarnya guru adalah menyampaikan mata pelajaran dan bertanggung jawab untuk membimbing siswa. ${ }^{7}$ Guru adalah tonggak yang terdepan dalam pembentukan Sumber Daya Manusia (SDM) yang berkualitas dan sebagai pengganti penerusnya nanti. ${ }^{8}$ Saat ini, guru hanya dipandang mengejar materi bukan mengajar dari hati. ${ }^{9}$

Kurikulum dijadikan sebagai alat untuk mencari keuntungan ekonomi, tanpa memikirkan output dari hasil kurikulum tersebut. Saat ini, banyak Mahasiswa-Mahasiswi merana, gara-gara selesai kuliah hanya menganggur. Bagi wanita, mencari pria idaman saat ini adalah yang sudah berstatus Pegawai Negeri Sipil (PNS) agar cerah masa depan nanti. Begitu juga halnya dengan kriteria pilihan orangtuanya. Berbeda halnya dengan tahun zaman 80-an, mencari pria idaman yang tahu mengaji agar bisa membimbing untuk di dunia dan di akhirat. Hal ini, juga terjadi pada orangtua perempuan zaman dahulu. Pria datang ke rumah perempuan yang ditanya adalah agamanya, saat ini pria datang ke rumah perempuan yang ditanya adalah pekerjaannya.

Pria idaman yang didambakan oleh wanita saat ini, tidak terlepas dari satu syarat yang merupakan wajib bagi dirinya, yakni harus bermodalkan wajah cantik rupawan.

6 Yasraf Amir Piliang, Dunia Yang Telah Diliipat: Tamasya Melampaui Batas-Batas Kebudayaan (Bandung: Matahari, 2011), h. 10.

7 Hamzah B. Uno, Profesi Kependidikan problema, solusi, dan reformasi di Indonesia, (Jakarta: Bumi Aksara: 2008), h. 15.

8 Ace Suryadi, Pendidikan Investasi SDM dan Pembangunan isu Teori dan Aplikasi, (Jakarta: Balai Pustaka. 1999), h. 298.

9 Untuk lebih jelasnya, baca Aslan, Pumping Teacher Dalam Tantangan Pendidikan Abad 21., lagi proses penerbitan di UNISKA KAL-SEL. 
Jika tidak cantik atau biasa-biasa saja, tidak bisa mencari bahkan memilih, karena ia belum tentu dipilih. Berbeda halnya dengan pria zaman sekarang, tidak perlu bermodalkan wajah tampan, yang penting pekerjaan mapan, isi dompet bukan ribuan, tetapi jutaan bahkan ringgitan, sudah berhak untuk memilih calon gadis idaman.

Dari paparan diatas, jika dikaitkan dengan kurikulum saat ini adalah hilangnya ruh-ruh pendidikan pada anak didik, sehingga banyak yang kuliah pada Jurusan agama tetapi tidak mengajar agama, tetapi mengajar mata pelajaran umum dan bahkan lagi tidak memilih menjadi guru tetapi mencari pekerjaan lain yang mampu menopong kehidupan ekonomi dan keluarganya.

\section{Perubahan Kurikulum}

Manusia tidak terlepas dari grand sejarahnya., begitu juga halnya dengan kurikulum, tidak terlepas dari pembaharuan yang tujuannya hanya meningkatkan semangat belajar peserta didik dan melahirkan generasi yang berkualitias untuk menghadapi tantangan zaman.

Kurikulum di Indonesia sejak Indonesia merdeka yakni tahun 1945, dikenal sebagai "kurikulum pendidikan nasional yang telah beberapa kali mengalami perubahan, yakni pada tahun 1947, 1952, 1964, 1968, 1975, 1984, 1994, 2004, 2006”, bahkan saat ini sudah lahir kurikulum yang baru yang dikenal sebagai kurikulum 2013 atau tematik. Lahirnya kurikulum tersebut, tidak terlepas dari perubahan sosial masyarakat, baik pada ruang lingkup politik, ekonomi, budaya.

Kurikulum yang telah dibuat dan disahkan oleh pemerintah, dianggap belum mampu untuk meningkatkan hasil belajar siswa, sehingga, walaupun kurikulum itu dianggap sudah baku, tetapi dalam silabus dan RPPnya dianggap belum sesuai pada tingkat anak didik. Oleh karena itu, walau bagaimanapun, lahirnya kurikulum masih saja diangap tidak sempurna, sehingga dicari titik celah dari kelemahan kurikulum tersebut. Salah satu kelemahan yang tampak adalah mata pelajaran yang diberikan kepada anak didik, dianggap belum sesuai untuk tingkat perkembangannya, sehingga lahirnya kata pengembangan kurikulum.

Pengembangan kurikulum adalah melihat bagaimana kurikulum itu berjalan. Oleh karena itu, untuk mengembangkan sebuah kurikulum, seharusnya dilihat beberapa 
langkah, diantaranya "Perumusan Tujuan.; Menentukan Isi.; Memilih Kegiatan.; dan Merumuskan Evaluasi". ${ }^{10}$

Penelitian yang berkaitan dengan pengembangan kurikulum adalah penelitian yang dilakukan oleh Salamah dalam disertasinya. ${ }^{11}$ Disertasi tersebut, berkaitan dengan pengembangan kurikulum untuk meningkatkan hasil belajar siswa. Judul disetasinya adalah "Pengembangan kurikulum Holistik". Pengembangan yang dimaksud dalam kurikulum ini adalah sebuah perencanaan yang disusun dengan matang, selanjutnya diujikan di Madrasah Tsanawiyah Banjarmasin yang hasilnya dapat meningkatkan hasil belajar siswa. Kemudian yang dimaksud dengan holistik adalah suatu model yang dirancang dengan melihat berbagai aspek dari kondisi peserta didik, baik lingkungannya serta melihat potensi siswa baik dari "intelektual, spiritual dan emosional serta sosial" secara seimbang.

Selain itu, lahirnya kurikulum 2013 telah dilakukan penelitian juga oleh Sariono. ${ }^{12}$ Ia menjelaskan bahwa kurikulum 2013 ini adalah "kurikulum generasi emas". Maksudnya, kurikulum bukan saja menyiapkan materi pembelajaran dalam kelas, tetapi mengembangkan potensi manusia untuk menghadapi tantangan masa depan. Kurikulum dianggap sebuah perjalanan sejarah, yang dikarenakan kurikulum selalu berganti-ganti apabila pergantian Menteri. Bahkan ia menganggap kurikulum 2013 ini, apabila seorang pendidik mampu meningkatkan kompetensinya dalam mengajar dapat membawa perubahan besar pada pendidikan, seperti yang diamanatkan oleh kurikulum 2013 ini yakni "menjadi generasi emas di tahun 2045".

Artikel yang ditulis Sariono, menurut saya tidak setuju. Saya menganggap kurikulum 2013, belum juga mampu untuk melahirkan generasi emas, karena berbagai macam gejala yang telah ditimbulkan dari kurikulum sebelumnya yang dilakukan oleh anak-anak maupun pada remaja, dari tindakan kriminal sampai tindakan seksual. Belum lagi hasil dari kurikulum 2013 saat ini yang telah diujikan di kota-kota besar, masih belum terlihat hasilnya yang signifikan dalam perubahan sosial saat ini.

10 Samsila Yurni, H. Erwin Bakti," Pengembangan Kurikulum di Sekolah Dalam Upaya Meningkatkan Mutu Pendidikan," Laporan Hasil Penelitian Universitas Muhammadiyah Palembang Sumatra Selatan, Progran Studi Administrasi Pendidikan, (tth): h. 293-306.

11 Untuk lebih jelasnya baca Salamah, Pengembangan Model Kurikulum Holistik: Pendidikan Agama Islam Pada Madrasah Tsanawiyah, h. 1-138.

12 Lihat Sariono," Kurikulum 2013: Kurikulum Generasi Emas, h. 1-9. 
Joko Widodo, setelah ia resmi menjadi Presiden, berbagai macam program yang telah dibuat untuk mengubah pendidikan di Indonesia, bahkan ia ingin bangsa Indonesia ini sudah dapat merubah mindsetnya, yakni dengan "Revolusi Mental", sehingga punglipungli ribuan rupiah pun ditangani oleh Presiden, apalagi yang besar, begitulah tegasnya.

Memang benar, pungli di Indonesia ini tidak ada lagi, bahkan di kantor-kantor sudah ada spanduknya tidak menerima pungli. Akan tetapi, pungli memang sudah hilang, diganti dengan "pungsure" (pungutan suka rela). Dalam hal ini, saya menjelaskan pengalaman saya pada saat menemani keluarga, minta buatkan Paspor di Kantor Imigrasi. Tetapi kami mengalami antri yang begitu lama. Setelah ada orang baru yang datang lansung dipanggil oleh orang yang bertugas Imigrasi. Hal ini menimbulkan pertanyaan bagi saya. Oleh karena itu, saya selidiki orang tersebut, ternyata orang tersebut memberi "Pungsure" kepada petugas Imigrasi. Dengan adanya "Pungsure" ini, semakin cepat urusannya, padahal di depan sudah ada spanduk bertuliskan tidak menerima pungli. Ternyata, orang migrasi yang minta pungutan suka rela tersebut membuat hati saya tidak percaya dengan penampilannya, karena keningnya hitam menandakan orang yang beriman, memakai janggut yang menandakan mengikuti sunah Rasul. Tetapi itu hanya penampilan untuk urusan akhirat, untuk urusan muamalah uang yang menentukan.

Paparan ini, hanya ingin menjelaskan hasil dari pendidikan kurikulum, baik dari yang awal sampai sekarang ini, bahwa kurikulum tidak akan pernah menghasilkan generasi emas jika budaya tersebut tidak hilang. Dari kejadian ini, bukan saja ruh prinsip kurikulum hilang, tetapi ruh fungsi kurikulum pun ikut juga hilang.

Hal ini senada yang diutarakan oleh Akhmal Annas Hasmori, dkk bahwa kurikulum adalah budaya. ${ }^{13}$ Budaya tidak akan pernah hilang, karena budaya dibuat oleh manusia. Begitu juga halnya dengan budaya pungli berubah menjadi "pungsure". Budaya tersebut adalah hasil unsur, rasa dan karsa manusia.

Fungsi ruh kurikulum, pada dasarnya adalah sebagai "pendidikan umum, suplementasi, eksplorasi dan keahlian”. Kurikulum dianggap sebagai fungsi pendidikan umum adalah kurikulum yang bertujuan untuk mempersiapkan anak didiknya agar

13 Akhmal Annas Hasmori,dkk" Pendidikan, Kurikulum Dan Masyarakat: Satu Integrasi," Journal of Edupres, Vol. 1, (2011): h. 352. 
menjadi warga Negara yang baik dan menjunjung tinggi nilai-nilai pancasila dan Undang-Undang Dasar (UUD). Kurikulum sebagai suplementasi adalah kurikulum yang saling mengisi antara perbedaan siswa, sehingga tidak ada yang namanya identitas sosial. Kurikulum sebagai eksplorasi adalah kurikulum yang dapat mengembangkan minat dan bakat siswanya. Kurikulum sebagai keahlian adalah kurikulum untuk mengembangkan bakat sesuai dengan keahlian anak. ${ }^{14}$

Pendidikan adalah untuk memanusiakan manusia. Maksudnya, pendidikan adalah fitrah yang mengajarkan kebaikan bukan kejelekan. Jika kebaikan akan diajarkan maka hasilnya juga akan baik., jika kebaikan diajarkan tetapi didasari oleh materi maka akan menghasilkan calon anak didik yang materialistis, hedonis., jika kebaikan diajarkan dengan hati yang suka rela, maka akan menghasilkan anak didik generasi emas, yakni beriman dan bertaqwa dan beramal shaleh.

\section{Kesimpulan}

Kurikulum adalah sebuah program yang telah dibuat Pemerintah untuk diimpelentasikan di Sekolah-sekolah dengan tujuan menghasilkan anak didik yang sesuai dengan Undang-Undang Dasar 1945. Adanya perubahan kurikulum tersebut tidak terlepas dari pandangan ahli kurikulum terhadap filosofis, sosiologis, psikologis, budaya, ekonomi maupun polotik. Akan tetapi, besarnya pengaruh teknologi transportasi dan informasi kurikulum saat ini, sehingga kurikulum mampu menghadapi tantangan zaman tetapi tidak mampu menghasilkan output sesuai dengan zamannya.

\section{DAFTAR PUSTAKA}

Aslan. Pumping Teacher Dalam Tantangan Pendidikan Abad 21., di UNISKA KALSEL.

Hasmori, Akhmal Annas, dkk”. Pendidikan, Kurikulum Dan Masyarakat: Satu Integrasi," Journal of Edupres, Vol. 1, (2011).

14 Sariono," Kurikulum 2013: Kurikulum Generasi Emas,..., h. 1. 
Kartika, I Made. Pengertian Peranan dan Fungsi Kurikulum. FKIP: Universitas Dwijendra Denpasar, tth.

Muryono, Sigit. Empati: Penalaran Moral Dan Pola Asuh: Telaah Bimbingan Konseling. Yogyakarta: Cawan Mas, 2009.

Piliang, Yasraf Amir. Dunia Yang Telah Diliipat: Tamasya Melampaui Batas-Batas Kebudayaan. Bandung: Matahari, 2011.

Salamah. Pengembangan Model Kurikulum Holistik: Pendidikan Agama Islam Pada Madrasah Tsanawiyah. Yogyakarta: Aswaja Pressindo, 2011.

Sariono,”. Kurikulum 2013: Kurikulum Generasi Emas," E-Jurnal Dinas Pendidikan Kota Surabaya, Vol. 3, (tth).

Suryadi, Ace. Pendidikan Investasi SDM dan Pembangunan isu Teori dan Aplikasi. Jakarta: Balai Pustaka. 1999.

Uno, Hamzah B. Profesi Kependidikan problema, solusi, dan reformasi di Indonesia. Jakarta: Bumi Aksara: 2008.

Yurni, Samsila, H. Erwin Bakti," Pengembangan Kurikulum di Sekolah Dalam Upaya Meningkatkan Mutu Pendidikan," Laporan Hasil Penelitian Universitas Muhammadiyah Palembang Sumatra Selatan, Progran Studi Administrasi Pendidikan, (tth). 